\title{
Root system investigation in sclerophyllous vegetation: an overview
}

\author{
Giovanni Sanesi, ${ }^{1}$ Raffaele Lafortezza, ${ }^{1}$ Giuseppe Colangelo, ${ }^{1}$ Pasquale A. Marziliano, ${ }^{2}$ \\ Clive Davies ${ }^{3}$ \\ ${ }^{1}$ Dipartimento di Scienze Agro-Ambientali e Territoriali, Università di Bari A. Moro, Italy; \\ ${ }^{2}$ Dipartimento di Gestione dei Sistemi Agrari e Forestali, Università Mediterranea di Reggio \\ Calabria, Italy; ${ }^{3}$ Department of Architecture, Planning and Landscape, Claremont Tower, \\ Newcastle University, UK
}

\begin{abstract}
Sclerophyllous vegetation contributes to the formation of forest resources in the Mediterranean biome that in turn provides an important resource in terms of ecosystem services. Despite this, scientific knowledge of sclerophyllous vegetation, in particular with regard to their root systems, is fragmented. This review takes into account the research on below-ground sclerophyllous biomass in different contexts where there is a Mediterranean climate. In particular, the authors analyse the different investigative approaches used in studying roots, the main topics covered by research, and the relationships between root and shoot biomass. The review shows that there is a paucity of research on the root systems of sclerophyllous vegetation although there are examples of innovative technologies being applied to research questions. This review considers some key works in the literature, and provides useful information to address re-vegetation and reforestation programmes in the context of Mediterranean ecosystems.
\end{abstract}

\section{Introduction}

The Mediterranean biome is found in large stretches of the coast surrounding the Mediterranean Sea. It is also present in South America, the western coast of Southern Africa, California and the

Correspondence: Giovanni Sanesi, Dipartimento di Scienze Agro-Ambientali e Territoriali, Università di Bari A. Moro, via Amendola 165/A 70126 Bari, Italy.

Tel. +39.0805443023 - Fax: +39.0805442504 .

E-mail: giovanni.sanesi@uniba.it

Key words: Mediterranean woody species, woody species vegetation, belowground biomass, root/shoot ratio.

Received for publication: 27 February 2013.

Revision received: 1 June 2013.

Accepted for publication: 4 June 2013.

(C) Copyright G. Sanesi et al., 2013

Licensee PAGEPress, Italy

Italian Journal of Agronomy 2013; 8:e17

doi:10.4081/ija.2013.e17

This article is distributed under the terms of the Creative Commons Attribution Noncommercial License (by-nc 3.0) which permits any noncommercial use, distribution, and reproduction in any medium, provided the original author(s) and source are credited. south-western tip of Australia; between latitudes $30^{\circ}$ and $40^{\circ}$ North and South.

Usually, woody plants that have adapted to this biome tend to be less than three metres tall and have a relatively shrubby appearance in terms of life form (e.g. Phillyrea sp.) or in response to the environmental context (e.g. Quercus sp.). They have many of the characteristics of desert plants, notably the ability to adapt in various ways to help them survive hot dry summers. They tend to have evergreen leaves and these are often small. Leaves may be curled, with the stomata hidden among numerous hairs (trichomes, as in some oak species) on the concave underside of the leaf where they are protected from hot sun and drying winds. Many of the plants contain numerous volatile organic compounds (Fares et al., 2009). In the Mediterranean biome, these sclerophyllous formations are an important forest resource.

Only in Italy, sclerophyllous vegetation covers 690,811 hectares (ha) and represents $6.59 \%$ of total forest cover (IFNC, 2005). Vegatation largely consists of Quercus spp., Rhamnus alathernus L., Phillirea spp and Arbutus spp. These species form different types of woods, maquis or garrigue.

Despite the spread of these key elements of Mediterranean ecosystems and landscapes, their contribution to biomass is rather limited, most notably their below-ground biomass. The root biomass can be an important fraction of the total biomass and plays a key role not only in primary production, but also in providing ecosystem services (e.g. landscape, biodiversity, soil preservation, water catchment, etc.). Mediterranean ecosystems host a substantial plant biodiversity (this area contains the $20 \%$ of the known vascular plant diversity in the world) (Cowling et al. 1996, Klausmeyer and Shaw, 2009) and, at the same time, are particularly threatened by climate change (IPCC, 2007).

Jackson et al. (1996), in a global review on root systems in different terrestrial biomes, identified 253 research papers published in international journals. However, among these, only 11 referred to sclerophyllous vegetation (3 in Spain, 2 in other European countries, and none in Italy). Cairns et al. (1997), in other research involving root biomass in forests around the world, took into consideration more than 70 papers of which only one included sclerophyllous shrubs.

Moreover, few studies have taken into account the root systems of Mediterranean coniferous forests (Pinus halepensis L., P. pinaster Ait., $P$. pinea $\mathrm{L}$., etc.) which is another important forest-type, typical of the Mediterranean climate; an important exception is the work of Ganastas and Spanos (2005). The pine forests are often of anthropic origin or derived from secondary succession, and frequently include sclerophyllous vegetation in their understory.

A search conducted on SCOPUS (accessed 28 January 2013) took into consideration papers published by 2012 and the following search terms: MEDITERRANEAN and WOODY SPECIES and BELOW-GROUND BIOMASS and/or R00T BIOMASS. The search identified a growing number of papers that refer to the Mediterranean environment 
(Kummerow et al. 1990; Canadell and Roda 1991; Martinez et al. 1998; Lopez et al. 1998; Rey De Viñas et al. 2000; Lopez et al. 2001a, 2001b; Silva and Rego 2003; Lopez et al. 2003; Silva et al. 2003; Mattia et al. 2005). However, most of these studies concern oak species Quercus coccifera L. and Q. ilex L. and have been conducted in Spain and France. Part of the reason for the scarcity of research on below-ground biomass is due to the fact that this type of study requires significant investment and requires the total or partial destruction of the woody formations being studied. The scarcity of studies on Mediterranean shrubs also reflects the lack of economic interest in these formations over recent decades. This may be changing, however, as there is growing interest in sclerophyllous shrubs as ornamental species suited to warm and dry conditions (Gori et al., 2008; De Lucia, 2009).

The purpose of this paper is to provide an overview of the literature published by 2012 concerning woody formations with particular reference to below-ground biomass. In particular, it aims to review the different approaches and methods that have been used to investigate the root systems of sclerophyllous vegetation also in supporting afforestation and reforestation programmes in this environmental context (e.g. Caravaca et al., 2003; Bacchetta et al., 2012).

\section{Approaches to root investigation}

From a general point of view, methods for investigating root systems can be classified into two types: i) invasive or destructive; ii) non-invasive or non-destructive. These two main categories may have submethods (Table 1).

\section{Invasive or destructive}

\section{Total roots excavation and harvesting}

Historically, the excavation and collection of root systems has been the most common technique used for investigating root systems. This method requires measuring and describing the whole root system in terms of root diameters, distribution and architecture. This method is still in use, as witnessed by some recent studies (Schwartz et al., 2012; Luo et al., 2012). It is a technique that requires a lot of effort in terms of cost and time. It also leads to the total destruction of the roots and the consequent loss of plants after the investigation. All methods that involve the excavation of all or part of the roots need to separate the soil from the roots very carefully. This is a potential methodological weakness that can lead to an underestimation of the roots of limited thickness that can remain in the soil. To limit this problem, roots may be washed with water or subjected to washing with air through the use of specific equipment. This includes the use of air-jet equipment (Kummerow et al., 1977) and, more recently, an ultrasonic air-stream (Nadezhdina and Cermák, 2003; Zenone et al., 2008).

Data collection on roots systems can be performed at different levels according to the aims of the research and can include topics such as: biomass measures (above and below-ground), dendrological parameters (length and diameter of roots at different sections) and architecture analysis. Nevertheless, root excavation techniques can result in root length or biomass being under-estimated (Pierret et al., 2005).

The excavation of the roots is an indispensable means of validating non-invasive methods and is also a major source of information for 2D or 3D representation of the roots themselves.

In chaparral shrubs (California), Kummerow et al. (1977) studied the root system of different species thus identifying different spatial distribution models and root/shoot ratio. Root system was explored through hydrological excavation. A similar approach was applied in the Chilean matorral by Hoffman and Kummerow (1978).

Using a sieving method, Rey de Viñas and San Miguel Ayanz (2000) studied below-ground biomass of Quercus coccifera L. in Spain and used this to model root distribution in the soil profile. In Portugal, Silva et al. (2003) studied a total of 42 plants from 18 species through hydrological excavation and found different rooting patterns in terms of the ecological characteristics of different species.

Caravaca et al. (2003) undertook research in a re-vegetation programme of degraded lands in Portugal. Analysis was undertaken on Pistacia lentiscus and Retama sphaerocarpa L. seedlings with attention given to shoot and root biomass and, consequently, to root/shoot ratio.

Silva and Rego (2004) analysed data obtained in the same plots as their previous research; they considered the distribution of root and shoot biomass and found different root-shoot ratios in different types of regeneration. Usually re-sprouting plants show higher root biomass than seeders.

Di Iorio et al. (2005) used a total excavation approach to study the root architecture asymmetry of Quercus spp. on slopes in southern Italy.

Table 1. Classification of methods for investigating root systems.

\begin{tabular}{|c|c|c|c|}
\hline Approaches & Methodologies & Authors & Year of publication \\
\hline \multirow[t]{2}{*}{ Destructive } & Total roots excavation and harvesting & $\begin{array}{c}\text { Kummerow et al. } \\
\text { Hoffmann and Kummerow } \\
\text { Rey de Viñas and San Miguel Ayanz } \\
\text { Silva et al. } \\
\text { Caravaca et al. } \\
\text { Silva and Rego } \\
\text { Di Iorio et al. } \\
\text { Mattia et al. } \\
\text { Padilla and Pugnaire }\end{array}$ & $\begin{array}{l}1977 \\
1978 \\
2000 \\
2003 \\
2003 \\
2004 \\
2005 \\
2005 \\
2007\end{array}$ \\
\hline & Partial root excavation: soil cores, soil trenches and monoliths & $\begin{array}{l}\text { Martinez Garcia and Rodriguez } \\
\text { Kummerow et al. } \\
\text { Martinez et al. } \\
\text { Silva and Rego } \\
\text { Moreno et al. } \\
\text { Surovy et al. }\end{array}$ & $\begin{array}{l}1988 \\
1990 \\
1998 \\
2003 \\
2005 \\
2011\end{array}$ \\
\hline \multirow[t]{2}{*}{ Non-destructive } & Minirhizotons & Lopez et al. & 1998, 2001a, 2001b, 2001c, 2003 \\
\hline & Ground-penetrating radar & Zenone et al. & 2008 \\
\hline
\end{tabular}


The authors found a significant relationship between stem diameter at breast height and root volume, which was significantly higher in steepslope conditions. In southern Italy, Mattia et al. (2005) used the total excavation of shrub species (Atriplex halimus L. and Pistacia lentiscus) to evaluate the root density distribution in terms of root area ratio and soil reinforcement. The results showed that the biotechnical characteristics of these shrubs are comparable with those of some trees.

Padilla and Pugnaire (2007) studied the root system of different species in the southern Spain and analysed the rooting growth and the importance of rooting depth for seedling survival.

\section{Sample root excavation and harvesting (soil cores, soil trenches} and monoliths)

The excavation of trenches, also called the profile wall technique, allows researchers to make estimates of the roots by removing only a part of the plants hypogeous apparatus. This technique (root counts) allows for the estimation of biomass, the differentiation by class size, adequate representation of the development and architecture of roots, and the estimation of the maximum rooting depth.

Martinez Garcia and Rodriguez (1988) carried out one of the first estimations on vertical root distribution of roots in Spanish Matorral by investigating soil cores $(20 \mathrm{~cm}$ diameter, $12 \times 5$ lengths until $100 \mathrm{~cm}$ depth had been reached). Kummerow et al. (1990) coupled a soil core approach with trench digging in order to analyse the root biomass, root distribution and root season activity in French Garrigue dominated by Quercus coccifera. The soil core approach was used to extract samples at different depths to enable comprehensive root estimation. Martinez et al. (1998) using the same approach taken in their previous research (Martinez et al., 1988) to estimate below-ground biomass and production in terms of root/shoot ratio in a shrub community in sandy soil in Spain. Silva and Rego (2003) studied the distribution of roots in Mediterranean maquis using root counts on trench walls and soil cores, especially for the estimation of fine root biomass and fine root length. The methodology of root observation through trenches close to the plant enables images of structural roots to be secured using digital imaging. Surovy et al. (2011) adopted this approach in a cork oak tree in Portugal. Moreno et al. (2005) estimated the root length density of Quercus ilex using the soil core method (10 cm diameter) and soil profiles. They were able to estimate not only the vertical root distribution, but also the horizontal distribution in this species that was seven times the extent of the canopy in terms of the horizontal projection of the apparatus.

The excavation of trenches also means damage to plant life is limited and so favours plant conservation. In some cases, even in another environmental context, this approach provided the same values as those obtained with the soil core technique (Levillain et al., 2011). The use of a monolith method requires the excavation of large volumes of soil, especially in woody plant studies. This method is very expensive and is only used in special cases (e.g. Jackson et al., 1996). The literature review found very few studies (16 scores in SCOPUS for different forest contexts) that adopt this method, but no references were found to the Mediterranean environment.

\section{Non-invasive or non-destructive}

In order to reduce time and costs, in recent years, researchers have identified alternative and non-destructive techniques to be used to estimate the below-ground biomass.

\section{Minirhizotrons}

Roots can be observed through transparent interfaces with soil, such as the walls of transparent plastic tubes (minirhizotrons) inserted into the soil. Buckland et al. (1993) have shown that minirhizotron estimates are similar to the results obtained by the root length density measured in forest trees (core method). It allows roots to be detected over several months (Smit et al., 2000) in order to estimate the effects of tree age and season on root production (Baddeley and Watson, 2005).

In current research, rhizotrons are normally coupled with scanning devices for acquiring images. Data acquired by this technique are processed by dedicated software to obtain 3D images.

Lopez et al. (1998, 2001a, 2001b, 2001c, 2003) applied this approach in a Mediterranean holm oak forest to observe the spatio-temporal dynamics of fine roots in thinned and unthinned stands along a $60 \mathrm{~cm}$ profile over two years. The researchers quantified roots at different depths $(0-20 \mathrm{~cm}$ and $30-50 \mathrm{~cm})$.

\section{Ground-penetrating radar}

Ground-penetrating radar (GPR) can provide 3D images of coarse roots (starting with a diameter of approx. $20 \mathrm{~mm}$ ) from the soil surface down to a depth of several metres. Usually root distributions are measured by the use of a portable signal transmitter and receiver at a signal frequency of $450 \mathrm{MHz}$. The instrument is gradually moved over the soil surface along specified grid lines. Hruska et al. (1999) were one of the first groups to map tree root systems with GPR in a study carried out in a Central European forest of oak trees (Quercus petraea Liebl.). Butnor et al. (2001) applied GPR in the south-eastern United States and they concluded that the utility of current GPR technology for estimating root biomass is site specific, and that GPR is ineffective in soils with high clay or water content and at sites with rough terrain.

Stokes et al. (2002) wrote the GPR technique could be considered a valuable non-destructive tool for the arborist, but it still needs development, especially with regard to the softwaring applied to model $3 \mathrm{D}$ output images.

The only field experience in the Mediterranean was reported by Zenone et al. (2008) who studied a pine forest (Pinus pinea and $P$. pinaster) in a coastal area of Tuscany, Italy. The authors report that the GPR method can detect the distribution of tree roots with a high resolution, particularly in sandy soils. They also show that operating at multiple frequencies could help solve the current limitations of the method. The comparison of GPR transects in conditions of different water content helped to define the best periods for its use. GPR is influenced by the presence of soil water and, in general, depends on the status of soil conductivity. In Japan, Dannoura et al. (2008) analysed the roots of Cryptomeria japonica L. using GPR and they found a significant positive relationships between root diameter and parameters extracted from the resultant GPR waveform. These authors also reported that the soil water content was a crucial factor impacting the ability to detect roots with GPR. The utility of GPR to measure forest tree root biomass in situ is also reported by Butnor et al. (2001, 2003 and 2009) and Hirano et al. (2009 and 2012). It is clear that further investigation is needed to determine optimal conditions (e.g. water content) and analytical methods for using GPR to examine roots in forest sites.

\section{Geo-electrical measurements}

Recently, the differential electrical method has been used for fast measurement of conducting (absorbing) root surfaces. This method can also visualise fine roots. Electrical methods are based on capacitance or on resistivity. In the first approach, an impedance bridge is used between the base of the plant stem and underground electrodes (Chloupek 1977; Preston et al., 2004).

The resistivity approach is used to measure the ability of a body (ground and roots) to limit the transfer of electrical current. Al Hagrey (2007) applied this in preliminary research using electrical resistive tomography; he coupled resistivity measurement with software imaging to provide 3D models.

Amato et al. (2008) measured root distribution and biomass in situ in southern Italy by multi-electrode resistivity imaging on Alnus gluti- 
nosa L. and found a significant relationship between soil resistivity and tree root biomass, as well as a relationship with soil water content.

The same results were acquired also by Zenone et al. (2008) by ground-penetrating radar and electrical resistivity tomography in a pinewood forest.

\section{Main investigated topics}

Research related to the root systems of sclerophyllous vegetation is primarily organised into two main streams: i) evaluation of underground biomass into different components (e.g. fine roots, structural roots, etc.); and ii) distribution of the roots (depth, architecture, etc.). We only identified one paper that covered both categories (Mattia et al., 2005).

\section{Evaluation of below-ground biomass into different components}

The first studies on root systems were carried out in American Chapparal and Matorral by Kummerow et al. (1977) and Hoffman and Kummerow (1978). The research interest focused mainly on the depth of the roots in these arid environments, the relationship between below-ground and above-ground biomass, the amount of space explored by the roots, and the different distribution of roots in relation to the diameter. The distribution of the roots is a factor related to single species but, in terms of the horizontal projection, the root area always exceeds the shoot area. Furthermore, the density of fine roots is normally greater in the areas shaded by the shrub crowns.

In Mediterranean Europe, research has been carried out in different areas of the Iberian Peninsula. Rey de Vinas and San Miguel (2000) estimated the below-ground biomass in populations of Quercus coccifera and its distribution in the soil profile through identification of different diameter classes. Silva and Rego (2004) take into consideration the root distribution of several Mediterranean woody plants in Portugal and set up a correlation matrix between root and shoot biomass. They point out that distribution is also related to the plants' regenerative strategy (sprouters and seeders).

Caravaca et al. (2003) studied the effects of the application of urban compost on below-ground and above-ground biomass in shrub species (i.e. Pistacia lentiscus) in the arid south-eastern area of Spain and demonstrated that composted residue addition increases the production of shoot biomass and modifies the relationship between roots and shoots. More specifically, an increase in above-ground biomass is greater than that in the below-ground biomass.

\section{Distribution of the roots}

Research on root systems focused on the distribution of fine roots (in terms of pattern and spatial dynamics) as related to forestry practices, and, in particular, thinning. Carlier (1987) pointed out the crucial aspect of sectorialisation of coppice stools also in relation to root dynamics, architecture and distribution (cited in Giovannini et al., 1992). Lopez et al. (1998) analysed fine root dynamics in Holm oak (Quercus ilex) in a clear cut wood and demonstrated that in thinned plots there are more roots in the top $20 \mathrm{~cm}$ of soil than in control plots. They also analysed the fine root longevity between 35 and 471 days; the results were higher in the control plots than in thinned plots.

The same authors (2001a, 2001b, 2001c) determined the vertical distribution in a Holm oak over a 3 -year period in terms of fine roots. Fine roots, estimated as fine root density, fine root length and fine root area index, tend to decrease with increasing depth with the exclusion of the first $10 \mathrm{~cm}$ of soil. Seasonal fine root biomass presented a cyclic behaviour pattern with higher values in autumn and winter and lower in spring and summer. The production of new fine roots is highest in winter followed by a high mortality rate in spring. Silva et al. (2003) studied the root distribution of different Mediterranean woody plants, including sclerophyllous shrubs, and devised an empirical model in relation to vertical distribution, root length and root biomass. Padilla and Pugnaire (2007) studied the positive relationship between woody seedling survival during summer drought and maximum rooting depth. Surovy et al. (2011) acquired images of structural roots of Quercus suber L. and demonstrated the efficiency of digital imaging for providing evaluating root systems. Mattia et al. (2005) investigated the biotechnical characteristics of the roots of Pistacia lentiscus to the stabilisation of slopes in a Mediterranean environment; this is the only research paper on this topic.

\section{Relationship between roots and shoots}

In order to obtain some indication of the relationship between below-ground and above-ground biomass, and see what differences exist between the climates of Mediterranean forest environments and other evironments, we collected the results of previous research over the last decades. For each datum, we reported habitat/region, root:shoot biomass ratio (R:S), methods of investigation, plants investigated, and bibliographic source (Table 2). Analysis of the literature shows that the R:S ratio in the Mediterranean environment is greater than 0.4 with values that are sometimes even higher than unity. Cannell (1982) reported $0.26,0.25$ and 0.31 for coniferous, tropical and

Table 2. Research results about root:shoot biomass ratio in last decades.

\begin{tabular}{lcccc}
\hline Habitat/region & R:S ratio & Method & Species & References \\
Matorral (Chile) & 0.57 & Total excavation & Adenostoma fasciculatum Hook and Arn & Kummerow et al., 1977 \\
Matorral (Chile) & 0.44 & Total excavation & Arctostaphylos pungens Kunth & Kummerow et al., 1977 \\
\hline Matorral (Chile) & $0.3-0.4$ & Total excavation & Lithraea caustica Hook and Arn and others shrubs & Hoffmann and Kummerow, 1978 \\
Shrublands (Spain) & $2.2-2.7$ & Soil cores & Cistaceae and Labiatae & Martinez et al., 1998 \\
\hline Garrigue (Spain) & $2.6-4.7$ & Total excavation & Quercus coccifera & Rey De Viñas and San Miguel Ayanz, 2000 \\
Shrublands (Portugal) & 1.11 & Total excavation & Resprouters shrubs & Silva and Rego, 2004 \\
\hline Shrublands (Portugal) & 0.53 & Total excavation & Seeders shrubs & Silva and Rego, 2004 \\
Revegetation programme (Spain) & 0.57 & Total excavation & Pistacia lentiscus & Carvaca et al., 2003 \\
\hline Revegetation programme (Spain) & 0.64 & Total excavation & Retama sphaerocarpa & Carvaca et al., 2003 \\
\hline
\end{tabular}


deciduous forests respectively. Cairns et al. (1997), in a previous review, reported that the R:S of forest trees, independent of latitude, varies around 0.26 . Jackson et al. (1996) reported different results in a review paper taking into consideration approximately 250 references. The forest habitat with the smallest R:S is the temperate coniferous forest $(0.18)$, followed by tropical evergreen forest $(0.19)$, temperate deciduous forest $(0.23)$, boreal forest (0.32), and tropical deciduous forest (0.34). The highest R:S ratios were observed in tundra (6.6) and sclerophyllous shrubs (1.2). In this last context, the data range is very wide (0.3-5.0). Comparing data across different biomes, the highest $\mathrm{R}: \mathrm{S}$ ratios are typical of areas with unfavourable ecological conditions and where plant growth is limited by climatic and soil conditions. In these conditions, root biomass plays an important ecological role for the regeneration process of forest resources.

This statement is supported by former research carried out in environments where the major factor is water deficit that highlights that root biomass changes substantially from arid to humid systems. Generally, in drier conditions it is easier to found larger R:S ratios than in mesic environments (Walter, 1963; Pallardy, 1981; Chapin et al., 1993) especially for shrubs. This result it also supported by Schenk et al. (2002). These authors affirm that shrubs and semi-shrubs tend to dominate the driest ecosystems where they are deeply rooted and that below-ground biomass generally decreases with increasing rainfall.

It should be stressed, however, that the different literature sources allow only a general analysis and highlight trends because the studies often have different methodological approaches. It should also be remembered that most of the research took into consideration a limited number of plants and the way in which the analysis of the roots was undertaken could lead to errors in the exact detection and sampling of the plants' below-ground apparatus.

Jackson (2000) provided a synthesis of global rooting patterns and soil attributes and their use in global models to understand the role of root distributions for carbon, water, and nutrient fluxes and to improve the representation of below-ground processes in global models. The author provided a map that shows the proportion of root biomass globally in the upper $30 \mathrm{~cm}$ of soil.

\section{Conclusions}

The present overview identified the key approaches adopted in recent decades in the research on root systems in sclerophyllous plants in Mediterranean biome. Moreover, different approaches on above- versus below-ground biomass were found in literature. The data show that there is a paucity of research on root systems although there are applications of innovative technologies. In particular, there are few investigations on root systems in some vegetation types (e.g. shrub formations) and in some geographical contexts.

Few of the studies have an allometric character; this is important for the identification of total biomass taking into consideration the aboveground biomass and dendrometric variables.

Allometric functions are particularly important whenever the ecosystem services produced by Mediterranean (sclerophyllous) forests need to be estimated. Taking into account the methods of investigation, this overview shows that the destructive methods (e.g. total or partial extraction of the roots) are still largely predominant in the studies concerning the determination of biomass, but that nondestructive approaches (e.g. Minirhizotrons, ETR or GPR) may represent valid alternatives in studies related to the dynamics of growth of soil volumes penetrated by roots.

This review provides useful information to address revegetation and reforestation programmes in the context of Mediterranean ecosystems.

\section{References}

Al Hagrey SA, 2007. Geophysical imaging of root-zone, trunk, and moisture heterogeneity. J. Exp. Bot. 58:839-54.

Amato M, Basso B, Celano G, Bitella G, Morelli G, Rossi R, 2008. In situ detection of tree root distribution and biomass by multielectrode resistivity imaging. Tree Physiol. 28:1441-8.

Bacchetta G, Cao A, Cappai G, Carucci A, Casti M, Fercia ML, Lonis R, Mola F, 2012. A field experiment on the use of Pistacia lentiscus $L$. and Scrophularia canina L. subsp. bicolor (Sibth. et Sm.) Greuter for the phytoremediation of abandoned mining areas. Plant Biosyst. 146:1054-63.

Baddeley JA, Watson CA, 2005. Influences of root diameter, tree age, soil depth and season of fine root survivorship in Prunus avium. Plant Soil. 276:15-22.

Buckland ST, Campbell CD, Mackie-Dawson LA, Horgan GW, Duff EI, 1993. A method for counting roots observed in minirhizotrons and their theoretical conversion to root length density. Plant Soil. 153:1-9.

Butnor JR, Doolittle JA, Johnsen KH, Samuelson L, Stokes T, Kress L, 2003. Utility of ground-penetrating radar as a root biomass survey tool in forest systems. Soil Sci. Soc. Am. J. 67:1607-15.

Butnor JR, Doolittle JA, Kress L, Cohen S, Johnsen KH, 2001. Use of ground-penetrating radar to study tree roots in the southeastern United States. Tree Physiol. 21:1269-78.

Butnor JR, Johnsen K, Samuelson L, Pruyn M, 2009. Current applications of GPR in forest research. Proc. Symposium on the Application of Geophyics to Engineering and Environmental Problems (SAGEEP), Fort Worth, TX, USA, pp 904-13.

Cairns MA, Brown S, Helmer EH, Baumgardner GA, 1997. Root biomass allocation in the world's upland forests. Oecologia. 111:1-11.

Canadell J, Rodà F, 1991. Root biomass of Quercus ilex in a montane Mediterranean forest. Can. J. Forest Res. 21:1771-8.

Cannel MGR, 1982. World forest biomass and primary production data. Academic Press, London, UK.

Caravaca F, Figueroa D, Alguacil MM, Roldan A, 2003. Application of composted urban reside enhanced the performance of afforested shrub species in degraded semiarid land. Biores. Technol. 90:6570.

Chapin FS III, Autumn K, Pugnaire F, 1993. Evolution of suites of traits in response to environmental stress. Am. Nat. 142:S78-92.

Chloupek 0, 1977. Evaluation of the size of a plant's root system using its electrical capacitance. Plant Soil. 48:525-32.

Cowling RM, Rundel PW, Lamont BB, Kalin Arroyo M, Arianoutsou M, 1996. Plant diversity in mediterranean-climate regions. Trends Ecol. Evol. 11:362-6.

Dannoura M, Hirano Y, Igarashi T, Ishii M, Aono K, Yamase K, Kanazawa Y, 2008. Detection of Cryptomeria japonica roots with ground penetrating radar. Plant Biosyst. 142:375-80.

De Lucia B, 2009. Response of potted Australian ornamental plants to different soil water conditions. Acta Hort. 807:277-82.

Di Iorio D, Lasserre B, Scippa GS, Chiatante D, 2005. Root system architecture of Quercus pubescens trees growing on different sloping conditions. Ann. Bot. 95:351-61.

Fares S, Mereu S, Scarascia Mugnozza G, Vitale M, Manes F, Frattoni M, Ciccioli P, Loreto F, 2009. The ACCENT-VOCBAS field campaign on biosphere-atmosphere interactions in a Mediterranean ecosystem of Castelporziano (Rome): site characteristics, climatic and meteorological conditions, and eco-physiology of vegetation. Biogeosciences Discuss. 6:1185-227.

Ganastas P, Spanos I, 2005. Root system asymmetry of Mediterranean pines. Plant Soil. 278:75-83. 
Giovannini G, Perulli D, Piussi P, Salbitano F, 1992. Ecology of vegetative regeneration after coppicing in macchia stands in central Italy. Vegetatio. 99-100:331-43.

Gori R, Lubello C, Ferrini F, Nicese FP, Coppini E, 2008. Reuse of industrial wastewater for the irrigation of ornamental plants. Water Sci. Technol. 57:883-9.

Hirano Y, Dannoura M, Aono K, Igarashi T, Ishii M, Yamase K, Makita $\mathrm{N}$, Kanazawa Y, 2009. Limiting factors in the detection of tree roots using ground-penetrating radar. Plant Soil. 319:15-24.

Hirano Y, Yamamoto R, Dannoura M, Aono K, Igarashi T, Ishii M, Yamase K, Makita N, Kanazawa Y, 2012. Detection frequency of Pinus thunbergii roots by ground-penetrating radar is related to root biomass. Plant Soil. 360:363-73.

Hoffman A, Kummerow J, 1978. Root studies in the Chilean matorral. 0ecologia. 32:57-69.

Hruska J, Cermák J, Sustek S, 1999. Mapping tree root systems with ground-penetrating radar. Tree Physiol. 19:125-30.

IFNC, 2005. Inventario Forestale 2005. Available from: http:/www.sian.it/inventarioforestale/ Accessed: 22 December 2012.

IPCC, 2007. Climate Change 2007: synthesis report. Contribution of Working Groups I, II and III to the Fourth Assessment Report of the Intergovernmental Panel on Climate Change. IPCC, Geneva, Switzerland. Available from: http:/www.ipcc.ch/pdf/assessmentreport/ar4/syr/ar4_syr_frontmatter.pdf

Jackson RB, 2000. Root distributions and global models. Available from: http://biology.duke.edu/jackson/roots.htm

Jackson RB, Canadell J, Ehleringer JR, Mooney HA, Sala OE, Schulze ED, 1996. A global analysis of root distributions for terrestrial biomes. Oecologia. 108:389-411.

Klausmeyer KR, Shaw MR, 2009. Climate change, habitat loss, protected areas and the climate adaptation potential of species in Mediterranean ecosystems worldwide. PLoS ONE. 4:1-9.

Kummerow J, Krause D, Jow W, 1977. Root systems of chapparal shrubs. Oecologia. 29:163-77.

Kummerow J, Kummerow M, Trabaud L, 1990. Root biomass, root distribution and fine-root growth dynamics of Quercus coccifera L., in the garrigue of southern France. Vegetatio. 87:37-44.

Levillain J, M'Bou AT, Deleporte P, Saint-André L, Jourdan C, 2011. Is the simple auger coring method reliable for below-ground standing biomass estimation in Eucalyptus forest plantations? Ann. Bot. 108:221-30

López B, Sabaté S, Gracia C, 1998. Fine roots dynamics in a Mediterranean forest: effects of drought and stem density. Tree Physiol. 18:601-6.

López B, Sabaté S, Gracia C, 2001a. Annual and seasonal balance of fine root biomass of a Quercus ilex L forest. Plant Soil. 230:125-34.

López BC, Sabaté S, Gracia C, 2001b. Fine-root longevity of Quercus ilex. New Phytol. 151:437-41.

López BC, Sabaté S, Gracia C, 2001c. Vertical distribution of fine root density, length density, area index and mean diameter in a Quercus ilex forest. Tree Physiol. 21:555-60.

López BC, Sabaté S, Gracia C, 2003. Thinning effects on carbon allocation to fine roots in a Quercus ilex Forest. Tree Physiol. 23:1217-24.

Luo Y, Wang X, Zhang X, Booth TH, Lu L, 2012. Root:shoot ratios across China's forests: Forest type and climatic effects. Forest Ecol. Manage. 269:19-25.

Martinez F, Merino 0, Martin A, Garcia Martin D, Merino J, 1998.
Belowground structure and production in a Mediterranean sand dune shrub community. Plant Soil. 201:209-16.

Martinez Garcia F, Rodriguez JM, 1988. Distribucion vertical de las Raices del matorral de Donana. Lagascalia. 15:549-57.

Mattia C, Bischetti GB, Gentile F, 2005. Biotechnical characteristics of root systems of typical Mediterranean species. Plant Soil. 278:23-32.

Moreno G, Obrador JJ, Cubera E, Dupraz C, 2005. Fine root distribution in Dehesas of Central-Western Spain. Plant Soil. 277:153-62.

Ndezhidina N, Cermak J, 2003. Instrumental methods for studies of structure and function of root systems of large trees. J. Exp. Bot. 54:1511-21.

Padilla FM, Pugnaire FI, 2007. Rooting depth and soil moisture control Mediterranean woody seedlings survival during drought. Funct. Ecol. 21:489-95.

Pallardy SG, 1981. Closely related woody plants. In: T.T. Kozlowski (ed.), Water deficits and plants growth. Academic Press, New York, USA, pp 511-48.

Pierret A, Moran CJ, Doussan C, 2005. Conventional detection methodology is limiting our ability to understand the roles and functions of fine roots. New Phytol. 166:967-80.

Preston GM, McBride RA, Bryan J, Candido M, 2004. Estimating root mass in young hybrid poplar trees using electrical capacitance method. Agrofor. Syst. 60:305-9.

Rey De Viñas ICR, San Miguel Ayanz A, 2000. Biomass of root and shoot systems of Quercus coccifera shrublands in Eastern Spain. Ann. Forest Sci. 57:803-10.

Schenk HJ, Jackson RB, 2002. Rooting depths, lateral root spreads and below-ground/above-ground allometries of plants in water limited ecosystems. J Ecol. 90:480-94.

Schwarz M, Cohen D, Orb D, 2012. Spatial characterization of root reinforcement at stand scale: theory and case study. Geomorphology. 171-2:190-200.

Silva JS, Rego FC, 2003. Root distribution of a Mediterranean shrubland in Portugal. Plant Soil. 255:529-40.

Silva JS, Rego FC, 2004. Root to shoot relationships in Mediterranean woody plants for Central Portugal. Biologia, Bratislava. 59:1-7.

Silva JS, Rego FC, Martins-Loução MA, 2003. Root distribution of Mediterranean woody plants: a modelling approach. Plant Biosys. 137:63-72.

Smit AL, Bengough AG, Engels C, van Noordwijk M, Pellerin S, van de Geijn SC (eds.), 2000. Root methods. A Handbook. Springer, Berlin, Germany.

Stokes A, Fourcaud T, Hruska J, Cermak J, Nadezhdina N, Nadezhdin V, Praus L, 2002. An evaluation of different methods to investigate root system architecture of urban trees in situ, I. Ground-penetrating radar. J. Arboricult. 28:2-10.

Surový P, Ribeiro NA, Brasil F, Pereira JS, Oliveira MRG, 2011. Method for evaluation of coarse cork oak root system by means of digital imaging. Agrofor. Syst. 82:111-9.

Walter H, 1963. The water supply of desert plants. In: A.J. Rutter and F.H. Whitehead (eds.), The water relations of plants. John Wiley and Sons, New York, USA, pp 199-205.

Zenone T, Morelli GF, Teobaldelli M, Fischanger F, Matteucci M, Sordini M, Armani A, Ferrè C, Chiti T, Seufert G, 2008. Preliminary use of ground-penetrating radar and electrical resistivity tomography to study tree roots in pine forests and poplar plantations. Funct. Plant Biol. 35:1047-58. 